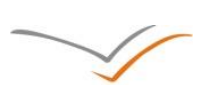

VERSITA

\title{
Invited Article: The Future of CRM is UX
}

Jakov (Yasha) Crnkovic

School of Business, State University of New York, New York, Albany, USA

\section{Abstract}

Background: This paper connects several sides of the web and mobile usages in business. The idea is to utilize Customer Relations Management (CRM) as the vehicle to establish connection from Web one and Web two into Web three. Objectives: This paper has the main purpose combine efforts in developing business strategies into general path of future Web development. Methods/Approach: Using the extensive literature, business cases and software trends in the area, the paper is focused on predicting the future in the area of the business trends in Information Technology (IT). Results: After discussion of the development using selected milestones: CRM is supported by the Social Networks (SN) and is enabled by Cloud Computing (CC), we were able to achieve the predictions. Conclusions: The final conclusion is in the convergence of the business efforts and SN methods on the new paradigm called the User eXperience (UX).

Keywords: Customer Relations Management, Supply Chain Management (SCM), Cloud Computing, Social Networks, User eXperience, Wallet-Share (WS)

JEL classification: $\mathrm{O} 32, \mathrm{O} 33$

Paper type: Research article

Received: 2, December, 2012

Citation: Crnkovic, J. (2013). "Invited Article: The Future of CRM is UX", Business Systems Research,Vol. 4, No. 1, pp. 4-13.

DOI: 10.2478/bsri-2013-0001

\section{Introduction}

The last 60 years of Information Technology (IT) evolved on a simple fact: if the business sees profitability from an idea or an IT discovery, IT will flourish!

There are millions of dollars spent in research without positive outcomes, which were not lucrative for their creators at all (for example, Xerox invented a mouse or VisiCalc with spreadsheet software), or spending in unsuccessful products (the "famous" flap with Windows Vista). Also, there are many good predictions with not so worthy business consequences for their inventors. For example, Kodak co-founder George Eastman had a vision: One day the camera would be small enough so everyone would carry one in a shirt pocket. The Galvins of Motorola had an equally vibrant vision: One day we would all be connected without wires (based on idea of Nikola Tesla, but not cited). Nortel's vision was that voice, data, and images would extend to every person and device in the world (Anderson, 2012).

Interestingly enough, companies mentioned above were the best run companies, but with making only a few bad decisions or forecasts. Many companies were able to reengineer and change management when needed. Furthermore, there are examples of the best solutions on the run; the best known example is IBM! Probably, somebody older remembered IBM's fight against PC computing, and then getting into PC computing business by "improving dumb terminals to be intelligent terminals" in mid-eighties, but still focusing on mainframes and proprietary software. Finally, they realized that there is no return to the "Big blue era", and started to focus on software and professional services, 
purchasing consulting and software companies and selling out their PC business and cutting old workforce, completely changing the company's profile! They change the whole approach to IT! The turbulent times are the main characteristics of the IT industry.

There are important individuals apart from Bill Gates or Steven Jobs. Probably, the best example (and possibly the proof that this statement holds) is related to the work by John Little, a Professor at MIT. Many people are familiar with the Little's formula in Operation management, but maybe not all of us are aware that he is the founder of Marketing Information System! It happened 40 years ago. At that time, this idea revamps, or better said, establishes the completely new IT landscape! Before that, computers in business were used for payroll, accounts payable and simple inventory problems. Accounting is necessary, but in fact, it is just correct history of a firm's data and not very useful for predictions and decision making! Payroll calculations are important to be done precisely and on time, but it is not adding value to the product or services. At the same time people worked in IT at that time (the "Electronic Computing Center") did not have or better to say, enjoy almost any creativity. IT was seen as boring and tiresome! Because of many special requirements for mainframes of that period, IT people were hidden in a company's basement and often seen as computer nerds (eating pizzas and drinking coke to survive the pressure of programming and coding)! The prevailing questions were: Can we use a computer to do something REALLY useful? Can we make a profit using IT? However, we are not interested in projects to "break even" using only intangible benefits! We need something to be a catalyst in the process! On the human side, where is the fun? In creativity! Compared with the situation today: which company is the best to work for? It is Google! Who is supporting creativity? IT companies of today!

There are millions big and small companies involved. This is happening now all over the world, not only in the US, Europe or Japan; it is going on here and now! While we are attending a conference, we are on SN, my TA back home is making a new app for the iPhone to play with stock market investments (not to comment about the Facebook stock-market debacle...); another person in Chicago is making app to find the best deal to fix your scratched car; somebody else is creating apps for your phone to "read" a newspaper for you by summarizing the facts, not to mention one old app, but my favourite one: app to find a good Italian restaurant based on the present location by providing a coupon "by one slice and get one free"...

The best thing of all is that we do not need to do IT development to be involved! How many of you already sent a picture or comment on the current event, lie TV show, a conference, maybe about this paper so far? How many of you voted on the Facebook link: "Like"? These steps are leading to UX! Maybe, somebody clicked dislike, which is not good for the company, but it is opening a dialogue; it is OK for UX! In reality, UX is not user EXCITEMENT but the user experience! The majority of those applications and comments are feeding the CRM!

\section{Customer Relations Management}

"If you don't have a strategy, don't spend a single cent. You're wasting your money." Charlene Li

From the mid-eighties, measurement of customer service and service quality started. There is continuous development of (already mentioned) marketing information systems, and introduction of complaint management. In the nineties, it is followed by making service improvement financially accountable ( $R O I$ and other models) and with the introduction of direct marketing and CRM! It led to the managing of customer lifetime value, long-term relationships and developing corporate strategies on service.

Selected concepts CRM, predicted over five years ago, like to replace the process of transactions with the process of relationships and to replace the mass marketing with the individualized approach are happening now, and all newer IT capabilities are supporting 
those ideas (Lovreta et al., 2010). We are witnessing huge changes in all business and technology areas. At the same time, CRM and SCM are being hit by the biggest quake: technology innovations (not only IT, but mostly from IT) and tsunami of data and it is even expected bigger one when RFID (Radio Frequency Identifier) goes "live" and in full speed!

Currently, RFID is slowly replacing the Barcode for selected products. It is relatively expensive, approximately $\$ 0.40$ per tag (which is OK for the container of TV sets, but imagine putting it on each small yogurt container costing only $\$ 0.35$ will be now $\$ 0.75$ ); also, there are no standards for coding and RFID is not eco-friendly at all. Where to store used RFID tags? Because of that, for now, RFID is placed only on larger packages and it allows more precise warehousing and transportation management. Some big companies require usage of RFID for "bulk" deliveries (for example, WalMart). Also, there are selected governmental applications by placing the RFID in passports (which is a bit controversial based on the "big brother" fears) and many commercial applications: from "tele-pass" or "easy-pass" (for charging tolls on highways), to "smart" swipe cards for public transportation, or in libraries (if the book has RFID, there is no need to check out books, a borrower will just walk through the door which is equipped with RFID antenna without the need even to show the Library card with the RFID code for it. An RFID tag may hold thousands of bits of data, comparing with Barcode with only 10 digits (with the standardized code system: producer is identified by the 5 and may use only 5 digits to make the individual product description). There is no "room" for a production site, date, order date, arrival date, etc.

At the moment, the use of RFID is generating big savings by avoiding errors based on wrong deliveries: RFID antenna will get all signals; the computer will compare them with the order and some RFID equipped products may send a message: "I was not ordered by this warehouse" even BEFORE the package is being touched (and unloaded from the truck)!!! Any change of location of the product with RFID tag generates new data: "I am here now"! IT needs to figure out where to put the enormous amount of new (how useful?) data in the CRM and also for the Supply Chain Management and Customer Relationship processes. Should we collect RFID data after sales and where to store them? Is it invasion of privacy? Is it useful for a customer to get information from the RFID tag on the bottle of milk saying: "I am expired", or that a message from the RFID antenna on the recycling container in your home after dumping an empty jar of your favourite strawberry jelly will be placed on your shopping list (known as a possible Web2 application), or maybe it should go directly to your shopping assistant in your preferred store (which is going towards Web 3 application)! Who will be in charge of decision making? Where to store RFID tags? There is a need for CC to storage data, to design software to sift through them (Data Mining and fast data searches), to use analytics to find the relevant data and eventually to make a profit from the whole operation (Business Intelligence/OLAP problem)!

The data explosion and accompanying data overload suggest the difficulty of storing and processing of vast amounts of data in real time and in context to provide actionable information. What about the data quality (Crnkovic et al., 2012)? For generations, the managers have made decisions based on exceptions - things that were out of line, unexpected, not normal. Future Bl systems will stick to this time-tested methodology, but will present exceptions in real time based on interpretative models and analytics that will present the exceptions with sharper, more usable background information and context. ... In contemporary organizations the flood of incoming data, much of it in various forms from social networks, Tweets, e-mail, white papers, PDFs, etc., is unintelligible to Business Intelligence systems, but that is changing quickly. As the improved capability of hardware combined with analytics start to extract meaningful insight from the muddy flow of data, answers to eternal questions such as "What do customers want?" and "How can we deliver it to them?" Are we coming closer and closer (Holstein, 2013), with a special input 
from SN: why somebody after spending two hours on a website decided NOT to purchase?

Years ago, we were taught to collect (purchase) the data to find the company's market share. Then: the fight is on! We need bigger market share! It is a real competition! We will get the biggest slice of pie, and they will lose! But now, this approach is obsolete. It's gone! In a global market, it does not work, period.

What works today is the Wallet Share (WS)! We can define it as a way to "make" the customer to spend as much as possible with our company. Think about any successful company, particularly use the eBusiness practices! The main characteristic of the Market Share strategy is based on creating a product and selling it to many different customers. The consequence is in expanding the customer base. There is a crucial role of simple SCM.

On the other side, the WS strategy implies that customer manager sells as many products as possible to one customer at a time, differentiate CUSTOMERS from each other, collaborate WITH customers, finds a constant stream of new business from established customers, use interactive communications to determine individual needs and send personalized messages! Also, it requires much more sophisticated SCM!

For example, Amazon started with a simple e-commerce selling CDs and books (by the way, who is purchasing CDs or printed books these days?) After "killing" many competitors Amazon sells almost everything, but what they really want is to sell are: downloads, AKA "pure fluff"! No warehousing problem, no workers and health benefits, no transportation (customer is doing everything: data entry, organizes payment, even pays for transportation) (customer needs high-speed Internet not to wait very long when downloading)! But, what a convenience for customers! They get an eBook in less than a minute (this is really Just-in-Time, especially by using a 1-click-ordering)! But this is just the beginning (sounds familiar from the infomercials): Amazon wants to make customer "hang on" and browse through their site as much as possible. There are several simple tools to do it: enormous amount of personalization (just for you), by giving a list of "other people who looked at this product and also considered other products". It is possible by using several programs and historical leftover data ("cookies"). More recently, they are very successful in selling services, for example, Amazon Cloud.

The next best example for the wallet share strategy is Dell. Dell's founder Michael Dell said almost 20 years ago, "De-Average customers!" The first association for Dell is PC, but their real business value is to offer a highly customized PC, PC for you! It means a customer gets his/her "own design". It means that customer will spend more because of the personalization. Then, Dell inserts special recommendations: it is better for you to buy 3 years on-site warranty (we know that, but it is additionally $\$ 289$, what a number). Here is the nature of WS: Dell did not name this process to be options or additions (those terms are associated with bad connotations, like when a car dealer tries to sell you the winter tires in Miami, Fl.), but Dell named it personalization! Something just for you, just for your own experience! Is it OK to mention the company Apple in the same paragraph? They dropped the word computers from their original name... CRM is all about branding! If you bought Apple computer, it is an extremely high probability that you will purchase iPhone or vice-versa! You are "their" customer now! You depend on them and they want to sell you more "stuff"! Facebook users "like" a brand, while the Twitter users "friend" a brand!

After discussion about the CRM strategy, let's say the WS approach is selected; the next point in CRM is getting the process right before choosing the Software. In fact it means a combination of re-engineering the management process, to focus how to avoid the strategic "Pain Points"; develop superior customer relationships and customer-centric performance. Very often, it means to create a new company's marketing strategy. Today, both CRM and SCM are customer-centric, not product centric.

It leads to another interesting issue: what is the most important group of people for your company? Before answering this question, let's do a simple quiz. Which do you put first?

... Shareholders? ... Customers? ... Employees? 
The winning answer is:

"My answer was very easy. You put your employees first. If you truly treat your employees that way, they will treat your customers well, your customers will come back, and that's what makes your shareholders happy. Ultimately, it's shareholder value that you are producing". This quote is by the Southwest Founder, Herbert "Herb" Kelleher. The focus of Southwest Airlines has always been on its people, regardless of how large they grow. The same ideas are shared by Sir Richard Branson (founder and owner of the Virgin Group of companies).

New CRM redefines conventional business thinking: "The customer is the King!" Likewise it introduces notion: the employees are also CUSTOMERS and should be treated like those! Many companies have established internal SN just for employees to be heard! Those SN is very practical and aimed for employee satisfaction! Imagine that there is a small problem in the store, for example: one light bulb is off and the major exhibit is in a dark! What will be more efficient to do? To find the manager and to tell him/her about the problem, then store manager will use the "line of command" and get a manager of a service support and ask him/her to send somebody to replace the bulb or just to publish on the internal SN: "We have a problem, anybody around to replace the bulb?"

The next question is who creates the added value and how? And the answer is: Employees who are the interface of the organization and its Customers, while the IT is ENABLING that to happen; IT is not the strategic advantage, but without it, the strategic advantage will not happen!

Frequently, companies see CRM as software or a tool in their tool kit just to be installed. Good CRM doesn't occur magically once the software is purchased and installed, so the strategic planning and research and design activities about an organization, technology solutions and IT infrastructure software selection will do the trick. These days, after establishing strategy, SaaS (Software As A Service) application will be selected. To see why, let's climb into the cloud!

\section{Any hurtles in the IT trend?}

In "good" old days, people in IS/IT areas planned solutions for the next period based on very expensive, both hardware (mainframes) and customized software solutions (programmed for just a single user)! The development time was very long; mistakes were present, management was mostly unhappy, typically with the costs: under those circumstances, it was impossible to prove that IT is not just a "pure" cost using any reasonable good methodology, like any Return Of Investment (ROI) model. As a consequence, if the programs (today, we like to call it software solutions) were successful, they were used to run for decades (Gendron, 2013).

In the more modern IT development, we have already seen miss conception: IT does not matter, we will put together something and it will work! But, without the vital role robust team for Systems Analysis and Design and good Project Management, we are witnessing the failures in building many IT/IS systems, particularly ERP systems. There are four typical reasons why those problems occur:

- Lack of software fit or the unbridgeable problems between software functionality and business needs.

- Unrealistic implementation expectations (the typical problem of savings with various resources and lack of organizational feasibility)

- Lack of championship by executives

Inclination to customize software rather than leverage standard functionality (actually this is a consequence of the "old" school of programming for individual user). It is known that the more customized software is more expensive and will take much more resources for implementation (for example, when "People Soft" begin to develop a software package to manage students' accounts for one big University, they started from the 
original HR database, the field: "employee name" was renamed to a "student name", etc.)

At the same time, IT practitioners and researchers are collecting reasons for failures in Cloud Computing (CC). Since it is the newest IT, but obviously, not all CC or other web based applications are always a great success. We expect that we will be able to underline the major problems of those failures in a few years, when people will gather much more data. Current discussion about this is more-less anecdotal.

Huge numbers of IT applications are developed on a daily base and people have a tendency to group them in the recognizable areas. What is the modern software solution? Can we predict which IT solutions will be used in the next period? What about its theoretical foundation?

In his recent article Andriole is trying to do exactly that: to predict IT trends for 2015. The article is published in 2012, creating the time frame of three years for prediction, assuming the future is five to seven years! He presents seven trends that will define the way we acquire, deploy, and support IT (Andriole, 2012):

(1) Rent-Don't Ever Buy-Software;

(2) Segment Users/Deploy Devices—and Align Devices, People, and Tasks;

(3) Invest in Analytics-Finally and Heavily;

(4) Respect Social Media-or Fail at Customer Service, Product Development, and Threat Assessment;

(5) Innovate-or Close the Doors;

(6) Go to the Cloud-and Align Your Core Competencies; and

(7) Federate-Put Technology (and Other Functions) Where IT Belongs.

As with any list of actions, the reader will say: I agree with some of them, and I disagree with the others.

For example, thinking about the first point (Rent-Don't Ever Buy-Software), there is even a newer option than Saas (which was probably in the readers' mind). It is data-as-aservice (DaaS)! We may look at that a special application of a Saas. In fact, Daas is made with the idea that data belong to the provider and the user has only access to data. For example (Fink, 2012), you don't need to collect your own data using a backyard weather station if you just want to know whether to pack a sweater or umbrella! The question is not who owns the data, but how to use them? Who is "the boss" of analytics? You can rent data (like in the case of Daas) or you can own the data using a bit different model known as dSaas model (Furht and Escalante, 2011).

Another typical discussion after seeing any list of options is to agree or disagree with the order in the proposed list. After reading all points, we may wish to reorganize the order of importance by moving the social media/social networks to the second position (Roblek et al., 2013).

Finally, why the year 2015 was quoted? It is the scheduled arrival date for the Web 3.0! It might be delayed due to chronic deficiencies in artificial intelligence (Andriole, 2012)?

Our next step is to "climb" into the cloud (this is an enabler of the final step), having in mind the subsequent step: Innovate by changing into UX!

\section{Enabler}

Cloud computing (CC) can be viewed as an enabler. It is distinct to be a special application offered with a high level of scalability as a service on the Web (Kaplan et al., 2012). Furht \& Escalante (2010) underlined the next advantages of the cloud computing technology are listed: cost savings (this is what decision makers like), high availability (like 99.9\%; this is what IT staff enjoys), and easy scalability (this is what developers love). CC is "taking care" not only about the Web, but about the mobile technologies, too. Do we have a "room" for several webs to exist in parallel or to cooperate?

In brief, cloud computing is presented as a layered computing architecture. The services offered through cloud computing usually include IT services referred as to SaaS, 
which is shown on top of the stack. Saas allows users to run the entire applications remotely from the cloud using a simple browser to access the application. It started as a part of the CRM (for example: salesforce.com) and nowadays covers not just the CRM, but the complete ERP applications (like NetSuite.com).

According to a Gartner Group estimate, SaaS sales in 2010 have reached \$10B, in 2011 increase to $\$ 12.1 \mathrm{~B}$ in 2011 , up to $20.7 \%$ from 2010. The Gartner Group estimates that SaaS revenue will be more than double its 2010 numbers by 2015 and reach a projected $\$ 21.3 \mathrm{~B}$. CRM is the largest market for SaaS. Saas revenue within the CRM market reached $\$ 3.8 \mathrm{~B}$ in 2011 (it was $\$ 3.2 \mathrm{~B}$ in 2010).

There are three other CC applications: Infrastructure-as-a-service (laaS), Platform-as-aService (PaaS), and the data-Storage-as-a-Service (dSaaS). All those applications are with important roles when the company is making a decision about the level of engagement in the CC.

There is no "silver bullet" in IT, and CC is not the one! There are many challenges connected to the CC (like with any infrastructure and software). We will leave these issues to other papers dealing with the security and vulnerability of systems.

\section{Social Networks}

Everything started from the e-commerce infant era. There is a huge amount of visitors, but no customers! It led to the question: How to make a visitor to become a customer? The "winning" answer is: to keep him involved! A company wishes to engage users, they need to make a user to SPEND in the store for merchandise or to order the services (think about WS)!

Apart from many software tricks, the real trick for success is to boost peer involvement, most likely by using the SN! When looking to reserve a room at a hotel, are you going to read the comments from actual guests? Quite frankly, some of the comments may be are not from the real guests but from "made up" guests to have better "grades"? One of the very interesting and important issues in SN is the question of TRUST!

The IT foundation enables developers to replace the Web 1.0 (known as static web pages) to the Web 2.0 which allows dynamic applications organized for Social Media. It helps us communicate a LOT faster (Fabac et al, 2011). The point is to communicate, not just to receive information from the Web. Have you participated in the survey to tell the company you're "after the purchase" experience? This means you are giving back; you are engaged in communication: sometimes because you are happy, probably more often because you are unhappy!

The social network relates to sharing of information, experiences and a perspective are here to stay. In 2008 (which we can name the infant era of SN), 394 million users watch video clips online (Tamar, 2009), while today there are single video clips viewed by billions! The number on the best known SN towards the end of 2012 is (from Smith, 2013): (i) Facebook: 1 billion users; 604 million mobile users; More than 42 million pages and 9 million apps; (ii) YouTube: 800 million users, 4 billion views per day, (iii) Twitter: 500 million total users, more than 200 million active users, (iv) Google+: 400 million registered users, 135 million active users, and (v) Linkedln: 200 million

That way we reached the point: Social network is all about COMMUNICATIONS. Having in mind mobile devices, and m-users available all the time, those numbers could be easily doubled!

COMMUNICATIONS and LISTENING will replace old fashioned SHOUTING, or traditional marketing sending messages over various outlets, mostly TV and newspaper ads: better to purchase it or else! Do you rather listen to the hullabaloo or to the gossip? In which of these two ways do you believe more? SN is sending gossip!

Social media are supporting a business! Like the hard core Web, it links B2C and B2B. The advantage is that $\mathrm{SN}$ sounds more trustworthy when talking about your business. It is helping to uplift the business, but also it raises the importance of the web and mobile 
businesses! During its development, people created a social network for almost every taste and demographic, but some of them are cluttered, or they are broad, covering too much of the "territory" and users do not feel comfortable. Some people may suggest that $\mathrm{SN}$ is becoming its own victim! It leads to the Renaissance of the "vertical" SN. From many vertical SNs, probably the best known is Linkedln, but many of them are with narrow various focuses, from healthcare to buildings and governmental issues for pet-lovers (cat lovers will not share the SN with dog lovers)! We can accept the list of SN characteristics developed by Li and Bernoff (2010): (i) Listening (probably the most important characteristic with usage in advertising and R\&D; (ii) Talking (people prefer to hear "real" voices than just to read about facts); (iii) Energizing (there are many examples of excited customers providing extra service for free by spreading a word about product, service, experience), (iv) Supporting (SN or SM is known as a huge supporting tools in many occasions), and ( $v$ ) Embracing (for the IT people, this is probably the most challenging to efficiently and effectively use customers' comments).

In January of 2013, a book about Facebook creator Mark Zuckerberg: "Think Like Zuck: The Five Business Secrets of Facebook's Improbably Brilliant CEO Mark Zuckerberg" will be available on-line and in print. In the book preview, there are five business secrets revealed: Passion, Purpose, People, Product, and Partnerships. We can have a serious discourse, whether Zuck is following those secrets or not! Maybe, it will be better to set up our "job" to compare those options with our vision and approaches when developing our business.

For decision making in the IT area, companies more or less trust industrial analysts from popular research groups, like Gartner, Forrester or Yankee. Should we TRUST them? For example, some analysts predict the stagnation of the Facebook (which is leaving the space to some other sites, like Google+, Twitter and Pinterest). Or, just a simple example, based on "industry insiders", what is the best computer security software on the market?

In what degree IT researchers are independent of the influences of the IT industry? Which company is credible enough giving valuable conclusions to be used in our decision making? One very good example from several years ago is about the software company Cyveillance. The company funded one of the industry research groups (they were not their clients at a time) for the so called "white paper" to "educate market", and not to serve as a promotional ad for Cyveillance (the company's name is mentioned only on the cover, as it is typical for "white" papers). It was not revealed how much money Cyveillance paid. From the ethical point of view, Cyveillance was not involved in editing the findings (fortunately for them, they were favourable). The practice of publishing "white papers" about companies who are clients of various industry research groups is a common practice. Having available "white papers" is useful, but IT research firms should explain their policies more transparent to their customers.

Let us compare this approach by using SN! Should a company (or news organization) let various opinions to be pasted without somebody from the company being involved with editing or at least with sifting through!

A relatively large number of companies are (still) using the Internet and even mobile options to push data out to users (known as shouting or traditional CRM) by telling them "what they should do" versus interacting with customers to develop a communication. Again, in this communication the most important part is listening to the customers. Customers are not shy: they would like to be involved; it is described with a new buzzword: user experience.

\section{User eXperience}

Focusing more on the Web 2.0, it is obvious that we live more and more in the virtual era! As a business person it is not easy to admit that complete social milieu is carried out as CC activity (Weinberg, 2009). A few years ago, we were trying to think is there was a day in our life without using a computer, the latest computer network, after that wireless network, 
then mobile devices. Today, a person not being active on SN could be compared to a person without TV twenty years ago! What IT is trying to do is to improve the experience when using all of the devices and it is the main ingredient of the Web 3.0!

IT people (and not only them, since it is collaborative work) work on Web 3 placing the relevance of date and their delivery to the client (user) with added a meaningful value to them. It is placing the individualized marketing on a higher level (the continuation of the idea about personalization of the product, but with help from the companies' software.) We already have elements of the trend with adjusting WWW pages toward the single users, various "friendly reminders", possibilities to manage several applications at home using Internet or mobile devices, like putting heat on or off, checking on a babysitter, with much wider use of RFID, home security systems and other devices. Our home computer becomes more than Siri! We will not need to ask, but it will go all the way around, using the semantic web to initiate discussion, even recognizing the relevance of the conversation!

Since the Web 3 goes towards the area of automation, some companies will try to solve the problem of moving into that level by hiring recognized software specialists or by purchasing a "canned" product when it is available. But, it is not strategic approach and it should be avoided! The solution is in creating a team of people to design and develop a Web 3 apps, as it already started (the future is here, ask Siri the widely known "personal phone assistant" application for iPhone, and eventually other Apple products and our home computer should become more than Siri! Remember, we have to ask Siri, but Web 3 turns that idea around!).

To create UX, you have to create an appealing UX. It should work for all web users, not your existing friends on the Facebook or customers, but for each person on the Web. That was Web 3 is fulfilling the role of combining and improving experiences!

Good UX requires partnership between many specialists. It is strategy, and you do not want to outsource it! This is a significant investment. One example how investing in user experience up front can result in significant savings in total cost of ownership is presented by IBM's estimation: every dollar spent on UX architecture up front will save $\$ 100$ in maintenance costs!

\section{Conclusion}

The whole idea of Web 2.0 and Web 3.0 is in turning a focus on the user. The goal of software, and technology as a whole, is to improve interaction that fosters understanding. We expect that Web 3.0 should deliver experiences tailored for everyone and automatically adjusts to each individual!

For the last 20 years, we have focused on creating robust back-end architectures and integration points. We have to build the foundation (there are issues within the area of the so called "Big Data") for great UX! The market, business and the consumer are now demanding that all should be focused to the end user. Are the IT people now moving all applications to be in fact very soft? Typically, the criticism is based on a short life span of a typical WEB 2 app's of around 18 months? Developers are using unproven methodologies, and some authors claim that those apps are built on sand (What happened with Facebook stock price a week after the launch, last week it was lingering around \$27 without signs to go up?)

It leads towards the conclusion that the concept of UX is much wider than Web 3 , while both, the Web 3.0 and CC, are two major ingredients. Obviously, UX will be focused on more integrated, multiple platforms, outlets and technologies. We are not afraid to predict and forecast. More, you do not need to think twice, the famous physicist and Nobel Prize winner of 1922, Niels Bohr was right stating, "Prediction is very difficult, especially if it's about the future". 


\section{References}

1. Anderson, H., (2012), "Why Did Kodak, Motorola, And Nortel Fail?" Information Week, January 12, Manhasset, NY, UBM-Tech.

2. Andriole, S.J., (2012), "Seven Indisputable Technology Trends That Will Define 2015", Communications of the Association for Information Systems, Vol. 30, No. 1, pp. 4.

3. Crnkovic, J., Pejic-Bach, M., and Tayi, G.K., (2012), "Impact of Information Attributes on Supply Chain Decision Making", presented at the DSI Conference, San Francisco, CA.

4. Fabac, R., Schatten, M., Đuričin, T. (2011), "Social Network Mixing Patterns In Mergers \& Acquisitions - A Simulation Experiment", Business Systems Research, Vol. 2 No. 1, pp.3644.

5. Fink, R. (2012), "Data: If You Don't Need to Own It, You Can Rent It", available at: http://www.saasintheenterprise.com/author.asp?section_id=2349\&doc_id=252 244 / (June, 2012).

6. Furht, B., Escalante, A., (Ed.) (2010), Handbook of Cloud Computing, New York: Springer.

7. Gendron, M.S., (2013), "Foreword", in Holstein, W. (Ed). Business Intelligence Applied: Implementing an Effective Information and Communications Technology, New York: Wiley.

http://www.mckinseyquarterly.com/Protecting_information_in_the_cloud_3041 /(June, 2012).

8. Kaplan, J., Rezek, C., Sprague, K., (2012), "Protecting Information In The Cloud", McKinsey Quarterly, available at:

9. Li, C., Bernoff, J., (2011), Groundswell: Winning in a World Transformed by Social Technologies, Boston, Harvard: Harvard Business School Press.

10. Lovreta, S., Berman, B., Petković, G., Veljković, S., Crnković, J. and Bogetić, Z., (2010). Menadžment odnosa sa kupcima (Customer Relationship Management), Beograd: Data Status.

11. Roblek, V. Pejić Bach, M., Meško, M., Bartoncelj, A. (2013). The impact of social media to value added in knowledge-based industries. Kybernetes. Accepted for publication.

12. Smith, C., (2013), "How Many People Use the Top Social Media, Apps \& Services?", available at http://expandedramblings.com/index.php/resource-how-many-peopleuse-the-top-social-media/ (June, 2012).

13. Weinberg, T., (2009), The New Community Rules: Marketing on the Social Web, Sebastopol: O'Reilly.

\section{About the author}

Professor Jakov (Yasha) Crnkovic is a member and former Chair of the ITM Department, School of Business, State University of New York, at Albany, NY. Prior to that, he was professor of IT/IS at the College Of Saint Rose, Albany NY, University at Binghamton, NY, University of Miami, Florida and the University of Belgrade. He received his BS, MS and PhD from the University of Belgrade. During his graduate work, he worked in CERN (Geneva, Switzerland) and at the Middlesex University (London, England). He published over 30 journal articles; he authored or co-authored over 20 textbooks, and published chapters in additional 10books. He participated in more than 75 conferences. He is doing consulting in the areas of information systems analysis and design, project management and operations management. His current research interests are in the areas of Decision Support Systems/BI, Supply Chain Management, Customer Relations Management and Data Quality. Author can be contacted at: jcrnkovic@albany.edu 